\title{
TERAPI SINGKAT BERFOKUS SOLUSI UNTUK MENINGKATKAN KEMAMPUAN PENETAPAN TUJUAN PADA NARAPIDANA YANG MENJELANG BEBAS
}

\author{
SOLUTION FOCUSED BRIEF THERAPY TO IMPROVE GOAL SETTING SKILL \\ INMATES WHO WILL BE RELEASED
}

\author{
Oleh: \\ Ni Made Putri Ariyanti ${ }^{1}$ \\ Hamidah $^{2}$ \\ Putu Nugrahaeni Widiasavitri ${ }^{3}$
}

Submitted:

20 November 2019

Revision:

24 Januari 2020

Accepted:

28 Januari 2020

\begin{abstract}
Inmates who will be released tend to experience psychological problems by worries about their future and the difficutly of getting a job after being released. Have a goals such as getting the job, desire to achieve the goals could increase optimism and positive feelings before release. Purpose of this study was to find effectivenesss solution focused brief therapy to improve goal setting in inmates who will be released in prison. This research used experimental design with one group pretest-posttest design. Research subjects were 13 inmates who will be released. This research used personal goal setting scale by Brunstein (1993) for measuring pretest and posttest goal setting inmates after intervention. This research had result that there was different goal setting score between pretest and posttest with sig. $0,022(<0,05)$. It means that solution focused brief therapy could improve goal seting in inmates who will be released in prison.
\end{abstract}

Keyword: Goal setting; Inmates who will be released; Solution focused brief therapy.

\begin{abstract}
ABSTRAK
Narapidana yang menjelang bebas cenderung mengalami masalah psikologis. Masalah ini disebabkan kekhawatiran dalam menghadapi masa depan yang tidak jelas dan sulitnya mendapatkan pekerjaan setelah bebas. Memiliki tujuan seperti mendapatkan pekerjaan yang diinginkan, ingin membahagiakan keluarga, ingin meraih cita-cita setelah bebas dapat meningkatkan optimisme dan perasaan positif menjelang bebas.Penelitian ini bertujuan untuk menguji efektivitas terapi singkat berfokus solusi untuk meningkatkan penetapan tujuan narapidana menjelang bebas di Lapas.Metode penelitian yang digunakan adalah penelitian ekspresimen one group pretest-posttest design.Subjek penelitian adalah narapidana menjelang bebas sebanyak 13 orang.Instrumen yang digunakan adalah skala personal goal setting dari Brunstein (1993) yang berfungsi untuk mengukur penetapan tujuan sebelum dan sesudah diberikan intervensi. Hasil penelitian menunjukkan adanya perbedaan skor pretest dan posttest dengan sig. $0,022(<0,05)$ yang berarti bahwa terapi singkat berfokus solusi dapat meningkatkan kemampuan penetapan tujuan narapidana menjelang bebas di Lapas.
\end{abstract}

Kata kunci: Narapidana menjelang bebas; Penetapan tujuan; Terapi singkat berfokus solusi.

\footnotetext{
${ }^{1}$ Ni Made Putri Ariyanti, Universitas Airlangga,putriariyanti95@gmail.com

${ }^{2}$ Hamidah, Universitas Airlangga, hamidah@psikologi.unair.ac.id

${ }^{3}$ Putu Nugrahaeni Widiasavitri, Universitas Udayana, putu_nugrahaeni@unud.ac.id
} 


\section{PENDAHULUAN}

Individu dewasa yang telah melakukan tindak pidana dan telah mendapatkan vonis untuk menjalani masa hukuman sesuai dengan putusan hakim disebut sebagai Narapidana. Pidana penjara merupakan suatu pembatasan kebebasan bergerak terhadap seorang terpidana, yang dilakukan dengan cara menutup seorang terpidana di dalam sebuah Lembaga Pemasyarakatan dan mewajibkan untuk menaati semua peraturan tata tertib yang berlaku di dalam Lembaga Pemasyarakatan, yang dikaitkan dengan suatu tindakan tata tertib bagi mereka yang telah melanggar peraturan tersebut (Priyatno, 2009). Sistem pemasyarakatan diselenggarakan untuk Narapidana agar individu menyadari kesalahan, memperbaiki diri, dan tidak mengulangi tindak pidana sehingga dapat diterima kembali oleh lingkungan masyarakat, dapat aktif berperan dalam pembangunan, dan dapat hidup secara wajar sebagai warga yang baik dan bertanggung jawab.

Menurut Bukstel dan Kilmann (dalam Bartol, 1994), pola reaksi psikologis yang dialami narapidana di Lembaga Pemasyarakatan menyerupai huruf U. Pertama kali menjalani hukuman atau pembinaan, narapidana harus beradaptasi dengan perubahan hidupnya di Lapas. Selama menjalani kehidupan di Lapas, narapidana juga mengalami berbagai masalah seperti konflik dengan sesama narapidana atau petugas Lapas. Tantangan untuk mencapai kesejahteraan psikologis semakin besar saat narapidana menjelang bebas dan akan kembali ke masyarakat.Menurut Kupers (dalam Kenemore \& Roldan, 2006), narapidana yang menjelang bebas cenderung mengalami masalah psikologis yang disebabkan kekhawatiran dalam menghadapi masa depan yang tidak jelas dan sulitnya mendapatkan pekerjaan setelah bebas. Hal ini disebabkan karena mantan narapidana yang telah keluar dari Lembaga Pemasyarakatan pada umumnya sangat sulit untuk mendapatkan pekerjaan dibandingkan sebelum menjalani masa hukuman (Hafida, 2004).

Penelitian ini dilakukan di salah satu Lembaga Pemasyarakatan (Lapas) di Bali. Wawancara awal yang dilakukan adalah dengan tiganarapidana yang menjelang bebas, petugas kesehatan di klinik lapas, dan sipir lapas. Berdasarkan hasil wawancara dengan narapidana yang menjelang bebas diperoleh bahwa sebagian besar narapidana merasa tidak memiliki harapan dan cenderung pesimis terhadap masa depannya. Hal ini sesuai dengan penelitian sebelumnya bahwa narapidana yang menjelang bebas memiliki kecemasan internal yang disebabkan oleh perasaan atau pikiran yang tidak menyenangkan terhadap masa bebas yang akan dihadapi yang ditunjukkan dengan perasaan tidak mampu, rendah diri, dan tidak percaya pada diri sendiri (Widiantoro, 2006). Pada umumnya, narapidana ingin menjalani kehidupan dengan normal setelah bebas dan tidak kembali ditahan karena tidak memiliki arah dan tujuan.

Keterangan juga diperoleh dari hasil wawancara dengan petugas kesehatan di Klinik Lapas dan Sipir Lapas bahwa banyak narapidana yang menjelang bebas mengeluhkan terkait hal yang dapat dilakukan di masa depan. Saat pemeriksaan kesehatan atau konseling singkat dengan petugas kesehatan atau sipir lapas, kebanyakan narapidana mengatakan sangat pesimis terhadap masa depannya dan membayangkan dirinya ditahan kembali karena tidak ada perencanaan untuk melakukan sesuatu di masa depan. Sehingga, perlu adanya penanganan psikologis berkesinambungan dan program yang konsisten khusus untuk perencanaan masa depan pada narapidana yang menjelang bebas.

Terdapat reaksi psikologis dan fisiologis yang dialami oleh narapidana menjelang bebas (Widiantoro, 2006). Reaksi psikologis adalah perasaan tidak aman, khawatir, bingung, tertekan dan kecewa. Sedangkan reaksi fisiologis yang dialami adalah sakit kepala, hilangnya nafsu makan, sulit tidur, dan mudah lemas. Dalamnya penderitaan yang dialami narapidana di dalam lembaga pemasyarakatan, dimungkinkan menimbulkan kondisi tekanan psikologis dan sakit fisik hingga mengakibatkan hilangnya semangat, harapan, tujuan hidup yang mengarahkan individu 
mengalami masalah-masalah psikologis. Bahkan, tidak ada lagi kepercayaan akan masa depan yang lebih baik.Narapidana merasa tidak memiliki arah dan tujuan untuk menjalani kehidupan setelah bebas. Hal ini dapat mendorong narapidana kembali melakukan perilaku kriminal dan menjadi residivis.Memiliki tujuan seperti mendapatkan pekerjaan yang diinginkan, ingin membahagiakan keluarga, ingin meraih cita-cita setelah bebas dapat meningkatkan optimisme dan perasaan positif menjelang bebas.

Tujuan dan harapan akan masa depan dalam masa pembinaan sangat berpengaruh terhadap kondisi psikologis narapidana itu sendiri. Menurut Lindforss dan Magnusson (1997), individu yang baru bebas dari penjara sering merasa tidak memiliki harapan dan tidak yakin dapat terhindar dari perilaku kriminal yang dapat membuat narapidana terhindar dari hukuman. Tujuan dan harapan pada narapidana dapat memberikan efek yang positif dalam mengurangi perilaku kejahatan dimasa yang akan datang (Douglas \& Vincent, 2006). Berdasarkan hasil penelitian Sari dan Nuqul (2017) bahwa narapidana yang memiliki tujuan akan masa depannya akan mengurangi resiko mengulang kembali kejahatan yang dilakukan dan mampu memandang dunia lebih baik, merasa diperlakukan dengan adil dan mengurangi potensi frustrasi.

Tujuan adalah sasaran atau cita-cita yang secara sadar diinginkan oleh individu untuk dicapai atau diperoleh (Locke \& Latham, 2006). Cochran dan Tesser (1996), secara komprehensif mendefinisikan tujuan sebagai gambaran kognitif dari cita-cita yang tersimpan dalam memori untuk perbandingan dengan kondisi yang baru terjadi, sebagai representasi masa depan yang mempengaruhi masa sekarang, sebagai keinginan kesenangan dan kepuasan yang diharapkan dari tercapainya tujuan, sebagai sumber motivasi dari tindakan. Terdapat sebuah teori kognitif dengan dasar pemikiran bahwa setiap orang memiliki suatu keinginan untuk mencapai hasil spesifik atau sebuah tujuan disebut sebagai penetapan tujuan (goal setting)(Locke \& Latham, 1990). Penetapan tujuan dapat menjadi daya dorong untuk memperbesar usaha yang dilakukan seseorang, bahwa seseorang akan bekerja lebih keras dengan adanya tujuan daripada tanpa tujuan (Locke \& Latham, 2006).

Penetapan tujuan personal (personal goal setting) adalah proses individu mengatur diri sendiri yang mempengaruhi perilaku individu untuk menetapkan tujuan personal (Grégoire, Bouffard, \& Vezeau, 2012). Dalam tujuan personal terdapat beberapa dimensi yang dibutuhkan agar individu dapat menetapkan tujuannya (Brunstein, 1993). Individu memerlukan komitmen yang terdiri dari determinasi, urgensi dan willingness serta memerlukan penilaian diri terkait pencapaian tujuan yang ditentukan yaitu kesempatan, kendali dan dukungan. Dengan adanya tujuan, individu dapat memahami hal yang paling diinginkan dan penting dalam hidupnya.

Latar belakang yang telah dipaparkan menunjukkan pentingnya penetapan tujuan pada narapidana yang menjelang bebas. Namun, kenyataannya tidak semua narapidana memiliki perencanaan dan penetapan tujuan menjelang bebas. Pentingnya narapidana menetapkan tujuan menjelang bebas akan memberikan dampak yang positif bagi individu dan masyarakat. Sehingga, narapidana yang menjelang bebas membutuhkan intervensi untuk menetapkan tujuan menjelang bebas sehingga dapat meningkatkan dan mempertahankan motivasi yang diperoleh melalui tujuan tersebut (Tripodi, Kim, \& Bender, 2010).

Salah satu intervensi yang tepat untuk meningkatkan penetapan tujuan pada narapidana menjelang bebas adalah dengan menggunakan terapi singkat berfokus solusi (solution focused brief therapy). Teknik intervensi yang dipilih dalam penelitian ini adalah pelatihan. Pemberian pelatihan dalam penelitian ini menggunakan metode yang bervariasi yaitu ceramah, diskusi, dan pengerjaan worksheet. Tujuan dilakukannya pelatihan ini adalah untuk memberikan informasi 
mengenai pemahaman pentingnya menetapkan tujuan menjelang bebas, melatih keterampilan untuk melakukan perencanaan tujuan secara soesifik agar peserta dapat menetapkan tujuannya.

Pendekatan Terapi Singkat Berfokus Solusi (SFBT) menekankan pada masa depan dan tujuan yang diinginkan oleh klien serta pada pencarian pemecahan (solusi) daripada masalah itu sendiri (Sharry, 2001). Terapi singkat berfokus solusi adalah pendekatan pragmatis yang berfokus pada masa depan dan pada tujuan yang ingin dicapai secara terstruktur dan dengan displin yang tinggi (De Shazer, Dolan, Korman, Trepper, McCollum \& Berg, 2007). Berdasarkan penelitian terdahulu, terapi singkat berfokus solusi dapat meningkatkan motivasi narapidana untuk menetapkan tujuannya, apakah tujuan untuk mendapatkan pekerjaan atau menghindari agar tidak kembali melakukan kejahatan (Lindforss \& Magnusson, 1997). Pendekatan berfokus solusi bermanfaat pada kelompok narapidana karena narapidana dapat memvisualisasikan keberhasilan dan motivasi untuk terhindar dari perilaku kriminal sehingga narapidana dapat terhindar dari hukuman.

Memperhatikan pentingnya goal settingpada narapidana menjelang bebas, maka peneliti melakukan penelitian dalam tujuan untuk melihat efektivitas terapi singkat berfokus solusi dalam meningkatkan penetapan tujuan pada narapidana yang menjelang bebas di Lembaga Pemasyarakatan X.

\section{METODE PENELITIAN}

Metode penelitian ini menggunakan pendekatan kuantitatif. Penelitian ini merupakan sebuah penelitian quasi experiment dengan menggunakan non-randomized one group pre-test post-test design. Pada desain ini, hanya terdapat kelompok eksperimen karena keterbatasan jumlah sampel yang terdapat pada Lembaga Pemasyarakatan X di Bali. Metode penggalian data dilakukan melalui observasi, wawancara, dan skala personal goal. Perlakuan dalam penelitian ini adalah pemberian intervensi dengan menggunakan. Peneliti ingin melihat efektivitas intervensi yang diberikan dengan membandingkan keadaan subjek sebelum dan setelah treatment dilakukan. Materi dalam intervensi ini disusun sendiri oleh peneliti berdasarkan teori dari terapi singkat berfokus solusi (De Shazer, Dolan, Korman, Trepper, McCollum \& Berg, 2007) yang menunjukkan manfaat yang signifikan pada narapidana dengan teknik miracle dan scaling question serta compliment (Berg, 2008).

Variabel dalam penelitian ini adalah penetapan tujuan (goal setting). Pengukuran variabel tergantung akan dilakukan dua kali yaitu sebelum dan setelah treatment untuk melihat apakah terdapat perbedaan skor dari skala personal goal (Brunstein, 1996). Pada skala personal goal yang asli dalam Bahasa Inggris menunjukkan adanya konsistensi internal yang baik. Hal ini dapat terlihat pada nilai koefisien alpha $(\alpha)$ secara keseluruhan yaitu 0,76. Secara khusus, koefisien alpha $\alpha$ juga terlihat pada nilai goal commitment yaitu 0,79 dan goal attainability yaitu 0,85 . Selain itu pada test-retest reliability dilakukan 10 minggu setelah pelaksanaan tes pertama. Nilai korelasi antara tes pertama dan tes kedua untuk goal commitment adalah 0,74 dan goal attainability adalah 0,73 .

Kuesioner personal goal memiliki rentang skor dari sangat tidak setuju (STS) yang diberi skor 1 sampai sangat setuju (SS) yang diberi skor 7. Kuesioner ini terdapat 12 pernyataan yang terdiri dari favorable dan unfavorable. Personal Goal memiliki dua aspek (Brunstein, 1993) yaitu aspek komitmen terhadap tujuan (goal commitment) dan pencapaian tujuan (goal attainability). Aspek yang menunjukkan komitmen individu dalam mengejar tujuannya (goal commitment) terdiri dari tekad (determination), keharusan yang mendesak (urgency), dan 
kehendak (willingness). Aspek mengenaievaluasi pencapaian tujuan (goal attainability) terdiri dari peluang (opportunity), kendali (control), dan dukungan (support).

Subjek narapidana yang menjelang bebas di salah satu Lembaga Pemasyarakatan di Bali. Jumlah sampel dalam penelitian ini adalah 13 orang. Kriteria subjek yang terlibat dalam penelitian ini adalah laki-laki dalam rentang usia 25 sampai 45 tahun, narapidana yang minimal satu bulan menjelang pembebasannya dan belum memiliki atau menetapkan tujuannya setelah bebas, dan narapidana menjelang bebas yang bersedia mengisi informed consent sebagai bukti tertulis kesediaan terlibat dalam penelitian.

Kegiatan intervensi ini terdiri dari 7 sesi. Pra-sesi: pengisian pretest. Sesi 1: penjelasan tentang tujuan, manfaat, serta prosedur pelaksanaan, sesi 2: pengenalan kemampuan penetapan tujuan, sesi 3: Identifikasi tujuan, sesi 4: identifikasi potensi positif dalam diri dan merefleksikan pengalaman positif dan negatif, sesi 5: identifikasi hambatan dan solusi dalam menetapkan tujuan, sesi 6: perencanaan tujuan, sesi 7: pengisian posttest. Analisis data kuantitatif yang dilakukan pada penelitian ini yaitu uji hipotesis. Uji hipotesis menggunakan uji beda menggunakan paired sample t-testuntuk mengetahui efektivitas Terapi Singkat Berfokus Solusi untuk meningkatkan kemampuan penetapan tujuan pada sampel penelitian.

\section{HASIL DAN PEMBAHASAN}

Uji asumsi yaitu uji normalitas dan lineritas dilakukan untuk memastikan tidak ada kesalahan dalam mengambil sample. Hasil uji asumsi menunjukkan bahwa data pada penelitian ini berdistribusi normal sehingga dapat dilakukan Analisa menggunakan paired sample t-test. Hasil analisis yang diperoleh adalah sebagai berikut:

Tabel 1.

Goal Setting Sebelum dan Sesudah Diberikan Pelatihan

\begin{tabular}{lcc} 
& N & Mean \\
\hline Pretest & 13 & 52,62 \\
\hline Posttest & 13 & 59,23 \\
\hline
\end{tabular}

Berdasarkan tabel 1. Diperoleh nilai rata-rata sebelum dan setelah pelatihan. Nilai ratarata yang diperoleh sebelum pelatihan yaitu sebesar 52,62 yang diperoleh dari hasil pretest. Adapun nilai rata-rata yang diperoleh setelah pelatihan yaitu sebesar 59,23. Terdapat selisih 6,61 dari hasil pretest dan posttest yang menunjukkan terdapat perbedaan kemampuan goal setting antara sebelum dan setelah pelaksanaan pelatihan.

Tabel 2.

Uji Normalitas (Shapiro Wilk)

\begin{tabular}{lc} 
& Sig. \\
\hline Pretest & 0,428 \\
\hline Posttest & 0,278 \\
\hline
\end{tabular}

Berdasarkan tabel 2. Uji normalitas data menggunakan Shapiro Wilk Test. Terlihat bahwa nilai signifikasi pada skor pretest adalah 0,428 dan skor posttest adalah 0,278. Data tersebut menunjukkan seluruh data terdistribusi secara normal (sig. > 0,05). Data hasil uji 
normalitas, terlihat bahwa sebaran data adalah normal sehingga untuk mengetahui adanya perbedaan dalam kelompok dilakukan dengan uji paired sample t-test.

Tabel 3.

Uji Hipotesis dengan Paired sample t-test

\begin{tabular}{cc} 
& Sig. \\
\hline Pretest-Posttest & 0,022 \\
\hline
\end{tabular}

Terpenuhinya uji asumsi normalitas memungkinkan data untuk dianalisis menggunakan uji paired sample t-test. Hasil uji paired sample t-testpada tabel 4. menunjukkan nilai sig. 2 tailed sebesar 0,022 (sig. < 0,05). Sehingga, hasil ini menunjukkan terdapat perbedaan skor goal setting sebelum dan sesudah pelatihan. Hal ini juga mengindikasikan bahwa pelatihan yang diberikan menggunakan pendekatan Terapi Singkat Berfokus Solusi adalah efektif untuk meningkatkan kemampuan goal setting.

Tabel 4.

Kategorisasi Goal Setting setelah Pelatihan Terapi Singkat Berfokus Solusi

\begin{tabular}{c|c|c|c}
\hline Kategori & $\begin{array}{c}\text { Daerah } \\
\text { Keputusan }\end{array}$ & Frekuensi & Presentase \\
\hline Rendah & $\leq 36$ & 0 & 0 \\
Sedang & $\mathbf{3 6} \leq \mathbf{X} \geq \mathbf{6 0}$ & $\mathbf{8}$ & $\mathbf{6 1 . 5 \%}$ \\
Tinggi & $\geq 60$ & 5 & $38.5 \%$ \\
\hline Total & & 13 & $100 \%$ \\
\hline
\end{tabular}

Tabel 4 menunjukan dominasi presentase goal setting narapidana menjelang bebas di salah satu Lapas di Bali termasuk dalam kategori sedang yaitu sebesar 61,5\%. Sedangkan 38,5\% masuk dalam kategori tinggi dan 0\% masuk dalam kategori rendah. Berdasarkan presentase ini, dapat juga diindikasikan bahwa 8 peserta bekategori sedang menunjukkan peserta telah mampu menemukan dan menetapkan tujuannya, memiliki komitmen (determinasi, kesediaan, dan urgensi) yang cukup untuk mencapai tujuannya yang dapat dilihat dari serta memiliki penilaian (kesempatan, kontrol, dan dukungan) yang cukup baik terhadap pencapaian tujuannya. Terdapat 5 peserta berkategori tinggi yang berarti peserta telah mampu menemukan dan menetapkan tujuannya, memiliki komitmen (determinasi, kesediaan, dan urgensi) yang tinggi untuk mencapai tujuannya serta memiliki penilaian (kesempatan, kontrol dan dukungan) yang sangat baik terhadap pencapaian tujuannya.

Hasil penelitian menunjukkan bahwa terdapat pengaruh signifikan terapi singkat berfokus solusi terhadap peningkatan keterampilan penetapan tujuan pada narapidana yang menjelang bebas. Efektivitas pelatihan dengan pendekatan Terapi Singkat Berfokus Solusi dapat diketahui dari nilai signifikansi sebesar 0,022 ( $\mathrm{sig}<0,05)$. Hasil penelitian ini sesuai dengan hasil penelitian sebelumnya yang dijelaskan oleh Walker (2010).

Penelitian Walker menunjukkan bahwa program Huikahi Circlemenggunakan pendekatan terapi singkat berfokus solusipada narapidana yang menjelang bebas cukup efektik untuk meningkatkan harapan dan sikap positif terhadap masa depan. Narapidana yang menjelang bebas memiliki optimisme dan pemahaman bahwa individu memiliki kontrol terhadap masa depannya. Hal ini sesuai dengan pernyataanDoekhie, Dirkzwager, dan Nieuwbeerta (2017) bahwa narapidana menjelang bebas yangmemperoleh wawasan tentang harapan di masa depan dan cara melakukan upaya awal terhadap tujuannya dapat 
meningkatkan keberhasilan transisi dari penjara ke kehidupan masyarakat dan tujuan jangka panjang.

Proses kegiatan intervensi ini berupa pemberian materi tentang penetapan tujuan (goal setting) agar narapidana yang menjelang bebas memahami pentingnya menetapkan tujuan menjelang bebas.Pelatihan dimulai dengan mengidentifikasi potensi positif diri dan merefleksikan pengalaman masing-masing individu. Masing-masing individu dapat merefleksikan pengalaman diri dan menuliskan potensi positif diri yang dimiliki. Menurut Walker (2008), mengidentifikasi potensi positif dalam diri dapat membantu narapidana menyadari hal yang dapat disyukuri dalam hidupnya yaitu kesempatan untuk belajar keterampilan baru dan mendapat pengalaman baru dari pengalaman hidupnya di dalam Lapas. Kemudian peserta diajak untuk mengidentifikasi tujuannya menggunakan scaling question. Peserta diminta untuk memberikan ranking tujuan dari yang paling memungkinkan untuk dicapai sampai tujuan yang kemungkinannya kecil untuk dicapai. Tujuan utama scaling question adalah untuk membantu klien untuk membuat tujuan yang dapat diidentifikasi, untuk membangun prioritas terhadap suatu tindakan, dan untuk mengetahui motivasi dan kepercayaan diri klien (Stander, 2003).

Peserta diminta untuk mengenal dan memahami diri sendiri dari perspektif peserta serta perspektif orang lain yang mengenal diri peserta. Hal ini bertujuan agar peserta mengetahui kelebihan dan kelemahannya sehingga dapat dikaitkan dengan hal yang ingin dilakukan dan menjadi tujuannya setelah bebas. Setelah peserta memahami dirinya, peserta diminta untuk mulai menetapkan tujuannya dan merencanakan langkah-langkah yang akan dilakukan dalam mencapai tujuannya serta mengidentifikasi hambatan yang mungkin akan dihadapi beserta solusi yang akan digunakan dalam mengatasi hambatan tersebut. Adanya kesadaran terhadap kemungkinan hasil yang negatif dapat mendorong narapidana untuk membayangkan secara realistis masa depannya dan mengarahkan narapidana untuk menghindari resiko di masa depan. Souza, Lösel, Markson, dan Lanskey (2015) menunjukkan bahwa pandangan yang realistis terhadap masa depan dan perencanaan terhadap tujuan adalah hal yang sangat penting akan keberhasilan dalam mengatasi dan menyesuaikan diri dalam menghadapi kesulitan.

Teknik-teknik yang digunakan dalam penelitian ini adalah miracle question, scaling questions, dan compliments. Miracle question digunakan untuk memperkenalkan bahwa masa depan dapat berubah-ubah dan untuk memulai menetapkan tujuan jangka pendek dan panjang di masa depan. Teknik membayangkan pada miracle question memberikan individu gambaran terkait solusi di masa depannya. Tujuan compliments adalah memberikan kalimat pujian atau pernyataan yang menunjukkan kekaguman atas hal yang telah individu lakukan atau saat individu menunjukkan usaha untuk memikirkan tujuan dan merencanakan cara agar tujuannya dapat tercapai.

Duwe (2017) menjelaskan bahwa kecil kemungkinan narapidana untuk melakukan kejahatan saat mereka memiliki tujuan dalam menjalani hidupnya setelah bebas dari tahanan, memiliki pekerjaan yang stabil dan menjadi minat individu serta memiliki potensi karir. Berdasarkan hasil wawancara dengan subjek penelitian, bahwa setelah mengikuti kegiatan intervensi ini, peserta dapat membayangkan kehidupannya setelah bebas, merasa semangat untuk menjalani kehidupannya karena telah menemukan dan menetapkan tujuannya. Menurut Vernick dan Reardon (2001), narapidana yang menjelang bebas menganggap keterlibatan mereka dalam program vokasional dan perencanaan tujuan menjelang bebas sebagai metode untuk perbaikan dan pengembangan diri, dapat membentuk keterampilan dalam perencanaan dan berpikir optimis sehingga membuat mereka yakin bahwa setelah kembali ke masyarakat akan menjalani kehidupan yang mandiri dan positif. 


\section{KESIMPULAN}

Kesimpulan dari penelitian ini adalah pelatihan dengan pendekatan Terapi singkat berfokus solusi cukup efektif untuk meningkatkan keterampilan goal setting pada narapidana menjelang bebas di salah satu Lembaga Pemasyarakatan di Bali.Hal ini dapat diketahui dari nilai signifikansi yang didapatkan pada uji beda. Secara individu, keterlibatan peserta memengaruhi hasil pelatihan. Peserta yang terlibat secara aktif dalam kegiatan ini cenderung memiliki skor penetapan tujuan yang meningkat, dan sebaliknya peserta yang kurang terlibat aktif cenderung tidak mengalami peningkatan skor penetapan tujuan. Secara keseluruhan, Narapidana mengetahui dan menyadari akan melakukan apa setelah bebas seperti kembali bekerja di tempat sebelumnya, membuka usaha serta mengembangkan usaha yang telah dibangun, melakukan hobinya dengan serius. Narapidana menunjukkan semangat, pikiran dan sikap positif terhadap masa depannya setelah bebas dibandingkan sebelum diberikan intervensi.

Berdasarkan hasil penelitian ini, dapat disarankan kepada Lembaga Pemasyarakatan agar programyang bertujuan untuk meningkatkan keterampilan dalam penetapan tujuan pada narapidana yang menjelang bebas dapat lebih banyak dilakukan. Terdapat berbagai metode yang dapat diterapkan untuk meningkatkan kemampuan penetapan tujuan dan memberikan motivasi agar narapidana menjelang bebas memikirkan masa depannya seperti Huikahi Restorative Circles.

Bagi peneliti selanjutnya dianjurkan untuk dapat menambah jumlah subjek penelitian, sehingga dapat melakukan penelitian dengan metode yang sama menggunakan kelompok kontrol sebagai pembanding.

\section{DAFTAR PUSTAKA}

Bartol, C. L. (1994). Psychology and Law. California: Wadsworth Inc.

Berg, I. (2008). Interviewing for solutions. Belmont: Thompson.

Brunstein, J. C. (1993). Personal goals and subjective well-being: A longitudinal study. Journal of personality and social psychology, 65(5), 1061.

Cochran, W., \& Tesser, A. (1996). The "what the hell" effect: Some effects of goal proximity and goal framing on performance. Dalam L. L. Martin \& A. Tesser (Eds.), Striving and feeling: Interactions among goals, affect, and self-regulation (p. 99-120). Lawrence Erlbaum Associates, Inc.

De Shazer, S., Dolan, Y., Korman, H., Trepper, T., McCollum, E., \& Berg, I. (2007). More Than Miracles The State of the Art of Solution-Focused Brief Therapy. New York: The Haworth Press, Inc.

Doekhie, J., Dirkzwager, A., \& Nieuwbeerta, P. (2017.). Early attempts at desistance from crime: Prisoners' prerelease expectations and their postrelease criminal behavior. Journal of Offender Rehabilitation, 56(7), 473-493.

Douglas, K. S., Vincent, G. M., \& Edens, J. F. (2018). Risk for criminal recidivism: The role of psychopathy. In C. J. Patrick (Ed.), Handbook of psychopathy (p. 682-709). The Guilford Press. 
Duwe, G. (2017). The use and impact of correctional programming for inmates on pre-and post-release outcomes. US Department of Justice, Office of Justice Programs, National Institute of Justice.

Grégoire, S., Bouffard, T., \& Vezeau, C. (2012). Personal goal setting as a mediator of the relationship between mindfulness and wellbeing. International Journal of Wellbeing, 2(3), 236 -250.

Hafida, A.N. (2019). Pengaruh faktor risiko dan protektif terhadap resiliensi pada klien pemasyarakatan di bali pemasyarakatan di bali pemasyarakatan kelas I Surabaya (Skripsi, tidak diterbitkan). Universitas Airlangga: Surabaya.

Kenemore, T. K., \& Roldan, I. (2006). Staying straight: Lessons from ex-offenders. Clinical Social Work Journal, 34(1), 5-21.

Lindforss, L., \& Magnusson, D. (1997). Solution-focused therapy in prison. Contemporary Family Therapy, 19(1), 89-103.

Locke, E. A., \& Latham, G. P. (2006). New directions in goal-setting theory. Current directions in psychological science, 15(5), 265-268.

Locke, E., \& Latham, G. (1990). A theory of goal setting \& task performance. Englewood Cliffs: Prentice Hall, Inc.

Markson, L., Lösel, F., Souza, K., \& Lanskey, C. (2015). Male prisoners' family relationships and resilience in resettlement. Criminology \& Criminal Justice, 15(4), 423-441

Priyatno, D. (2009). Sistem Pelaksanaan Pidana Penjara di Indonesia. Bandung: PT Refika Aditama.

Sari, L. L., \& Nuqul, F. L. (2017). Pengaruh harapan terhadap kecenderungan residivis pada narapidana. Idea: Jurnal Psikologi, 1(1), 35-40.

Sharry, J. (2001). Solution-Focused Group Work. London: Sage.

Souza, K. A., Lösel, F., Markson, L., \& Lanskey, C. (2015). Pre-release expectations and post-release experiences of prisoners and their (ex-) partners. Legal and Criminological Psychology, 306-323.

Stander, I. (2003). The impact of solution-focused brief therapy on young youth offenders (Tesis tidak diterbitkan). Stellenbosch University: Stellenbosch.

Tripodi, S., Kim, J., \& Bender, K. (2010). Is employment associated with reduced recidivism? The complex relationship between employment and crime. International Journal of Offender Therapy and Comparative Criminology, 54(5), 706-720.

Vernick, S. H., \& Reardon, R. C. (2001). Career development programs in corrections. Journal of Career Development, 27(4), 265-277. 
Walker, L. (2008). Implementation of Solution-Focused Skills in a Hawai'i Prison. In P. D. Jong, \& I. Kim Berg, Interviewing For Solutions. Belmont: Nelson Education.

Walker, L. (2008). Implementation of solution-focused skills in a Hawai'i Person. In P. De Jong, \& I. Kim Berg, Interviewing for solutions (pp. 302-308). Belmont, CA: Thompson/Brookscole.

Walker, L. (2010). Huikahi Restorative Circles: Group Process for Self-Directed Reentry Planning and Family Healing. European Journal of Probation, 2(2), 76-95.

Widiantoro, W. (2006). Kecemasan Narapidana Saat Menghadapi Masa Menjelang Bebas (Studi Kasus Pada Narapidana Di Lembaga Pemasyarakatan Kelas 1 Sukamiskin Bandung) (Skripsi tidak diterbitkan). Yogyakarta : Universitas Sanata Dharma. 